$\$$ Research Square

\title{
Multifocal Intraocular Lens Exchange in Patients with Ocular Comorbidities: Indications and Outcomes
}

Brian Kenny Armstrong ( $\square$ bkarmstrong@gmail.com )

Cleveland Clinic Abu Dhabi https://orcid.org/0000-0001-6337-6265

Jason Goldsmith

Cleveland Clinic Abu Dhabi

Terrence Lee St John

Cleveland Clinic Abu Dhabi

Samuel Navon

Cleveland Clinic Abu Dhabi

\section{Research Article}

Keywords: multifocal IOL intolerance, trifocal IOLs, IOL exchange, ocular comorbidities, patient dissatisfaction

Posted Date: March 13th, 2021

DOl: https://doi.org/10.21203/rs.3.rs-284924/v1

License: @ (1) This work is licensed under a Creative Commons Attribution 4.0 International License. Read Full License 


\section{Abstract}

Purpose: To investigate all cases of multifocal intraocular lens (MFIOL) exchange, with specific focus on indications for exchange and evaluation of postoperative outcomes, in a tertiary care, multi-specialty ophthalmology practice.

Setting/Venue: Academic Referral Center/Cleveland Clinic Abu Dhabi - Abu Dhabi, United Arab Emirates

Methods: This retrospective case series identified all patients that presented to a large academic practice over a 4-year period that were intolerant to MFIOL technology and thus required intraocular lens $(\mathrm{IOL})$ exchange. All patients reported poor vision despite correction of reversible ocular comorbidities, including dry eye and residual refractive error. Outcomes reviewed include subjective visual complaints, IOL-type, visual acuity, refractive error, ocular comorbidities, and surgical outcomes. Endpoints examined include mean uncorrected distance visual acuity (UDVA), mean corrected distance visual acuity (CDVA), mean refractive spherical equivalent (MRSE), and residual refractive astigmatism.

Results: Six eyes of five patients required MFIOL exchange. All IOL's exchanged were trifocal IOL's. IOL exchange occurred between 6 to 72 months following primary phacoemulsification. Each patient had multiple ocular comorbidities, ranging from keratoconjunctivitis sicca to longstanding intermediate uveitis and macular pathology. Postoperatively, subjective visual complaints resolved in all patients. Objective mean changes in UDVA, CDVA, MRSE and residual astigmatism were not statistically significant.

Conclusion: Thorough preoperative evaluation is required prior to MFIOL placement in order to rule out ocular comorbidities that may impair visual quality. In patients with MFIOL intolerance due to irreversible ocular comorbidities, IOL exchange to a monofocal IOL is safe, effective, and results in subjective improvement in vision.

\section{Introduction}

Multifocal intraocular lenses (MFIOLs) utilize a variety of optical designs to correct presbyopia in pseudophakic patients. Common MFIOLs, such as bifocal intraocular lenses (BIOLs), trifocal intraocular lenses (TIOLs) and extended depth of focus (EDOF) intraocular lenses (IOLs) work by diffracting light into 2 or 3 foci, or by providing a continuous range of focus, respectively. Of the MFIOL design variants, TIOL's provide the highest levels of spectacle independence because they enable excellent intermediate visual acuity (VA) without adversely effecting distance or near VA [1-4]. However, there is evidence that some patients are intolerant of MFIOL technology, either due to ocular comorbidities that impact visual quality, bothersome photic phenomena or difficulty with neuroadaptation [5-8].

The purpose of this study was to identify all cases of MFIOL exchange that occurred within an academic ophthalmology referral center over a specified time period, to investigate the reasons for IOL exchange, and to evaluate postoperative outcomes.

\section{Patients And Methods}

This retrospective chart review was performed with the approval of the Cleveland Clinic Abu Dhabi (CCAD) Institutional Review Board and conducted in accordance with the tenets of the Declaration of Helsinki. Patients and the public were not involved in the design, conduct, reporting, or dissemination plans of our research. A comprehensive electronic medical record review was conducted to identify all cases of MFIOL exchange at CCAD that occurred over a 4-year period from February 2015 through February 2019. The study included patients who had their cataract surgery performed at CCAD as well as patients that had surgery performed at outside facilities.

The data collected included patient demographics, ophthalmic history, type of primary MFIOL implanted, MFIOL fixation location, ocular comorbidities, surgical indication for IOL exchange, time interval between the surgeries, surgical complications, IOL exchange surgical technique, biometric method utilized, type of secondary IOL implanted, and postoperative follow-up range. Surgical indications were categorized as subjective visual symptoms such as blurred vision and/or photic phenomena (glares, halos, dysphotopsia).

Statistical analysis was performed using R version 3.5.1 statistical software (R Foundation, Vienna, Austria). Endpoints examined include mean uncorrected distance visual acuity (UDVA), mean corrected distance visual acuity (CDVA), mean manifest refractive spherical equivalent (MRSE) and residual refractive astigmatism. Sample mean and standard deviations were calculated for all pre- and postoperative time points. Inferential comparison of preoperative versus postoperative means were performed using paired-sampled ttests. To provide context for the size of mean change observed pre- to postoperatively, standardized mean differences were calculated by dividing pre- and postoperative mean difference by the respective pooled standard deviation. 


\section{Results}

We identified 6 eyes of 5 patients who underwent MFIOL exchange. All MFIOL's requiring exchange were AT LISA TIOL's (Carl Zeiss Meditec, Jena, Germany); there were no other TIOL's, BIOL's or EDOF IOL's that required explantation or exchange at CCAD during the study period. In 2 eyes of 2 patients, the primary AT LISA TIOL was initially implanted unilaterally at CCAD. In 4 eyes of 3 patients, the primary AT LISA TIOL was initially implanted at other medical facilities within the United Arab Emirates (UAE). Patient demographics are detailed in Table 1. There were 3 females and 2 males included in the study, and the mean age at time of IOL exchange was 53 years (range 36 to 67 years). In all 6 eyes, the primary TIOL was implanted into the capsular bag during phacoemulsification surgery. Only one eye incurred an intraoperative complication, which was a limited anterior capsule tear during phacoemulsification.

Prior to IOL exchange, the mean logarithm of the minimal angle of resolution (logMAR) for UDVA and CDVA was 0.48 (range 0 to 0.88 ) and 0.11 (range -0.13 to 0.47 ) respectively. MRSE was -0.77 diopters (D) (range -0.25 to -1.63 ), and 5 of the 6 eyes had residual refractive astigmatism > 0.5D. Visual acuity, refractive error, subjective patient complaints and ocular comorbidities for each patient are shown in Table 2.

Four out of 5 patients reported blurred vision in the operative eye at all distances (far, intermediate and near) that could not be ameliorated by treating reversible comorbidities, such as dry eye and residual refractive error. All eyes were found to have some degree of dry eye ranging from mild to severe, so dry eye treatment was initiated and escalated per an established dry eye management protocol [9]. All patients underwent manifest refraction and were either trial-framed or given full spectacle correction. The patients did not report satisfactory improvement in symptoms with either intervention. One patient reported positive dysphotopsia, manifesting as bothersome haloes around lights. Treatment with brimonidine tartrate $0.2 \%$ (Alphagan) eye drops as needed as well as blue light (470 $\mathrm{nm}$ ) filtering eyeglasses (WellnessPROTECT Eyewear; Eschenbach, CT, USA) produced only mild improvement in symptoms.

All eyes had multiple ocular comorbidities, ranging from Sjogrens Syndrome with keratoconjunctivitis sicca to longstanding intermediate uveitis and macular pathology. Of note, 5 of the 6 eyes had mild posterior capsular opacification (PCO) on presentation. Nd:YAG laser capsulotomy was not undertaken in any eye given the multitude of comorbidities in each eye - comorbidities that decreased the likelihood that Nd:YAG laser capsulotomy alone would resolve the patient's visual symptoms. Moreover, Nd:YAG laser capsulotomy was avoided due to the likelihood that these patients would require IOL exchange. IOL exchange in the setting of prior laser capsulotomy increases risk for intraoperative vitreous loss due to (a) the loss of compartmentalization of vitreous that is provided by an intact posterior capsule, and (b) rupture of the anterior hyaloid face by the laser treatment [10].

In all cases, the TIOL was exchanged for a monofocal IOL targeting emmetropia. Biometry was performed using the IOL Master 500 (V.7.7, Carl Zeiss Meditec) on the acrylic pseudophakia measurement setting. One case was calculated with the Holladay 1 formula on the IOL Master. One toric case was calculated using the Barrett Toric online calculator (V2.0; http://ascrs.org/barrett-toric-calculator). One case was calculated using the Holladay 2 formula on the IOL Master. The three remaining eyes were calculated with the Barrett Rx Exchange online calculator (V1.05; http://calc.apacrs.org/barrett_rx105/). Relevant parameters of IOL exchange are shown in Table 3.

The mean time interval between phacoemulsification and IOL exchange was 36.8 months (range 6 to 72 months). IOL exchange was performed by two surgeons (B.K.A and J.A.G). A two-handed technique was utilized with extensive visco-dissection to free the plate haptics from capsular attachments. In 2 eyes, a standard technique was utilized, whereby the primary TIOL optic was cut into multiple pieces and removed from the eye prior to implanting the monofocal IOL. In the remaining 4 eyes, an IOL scaffold technique was used [11] whereby the primary TIOL was repositioned into the anterior chamber, and the monofocal IOL was placed into the capsular bag prior to bisecting and removing the TIOL from the eye.

The 2 most surgically challenging eyes were from the same patient with bilateral intermediate uveitis and severe capsular fibrosis. This patient had his initial phacoemulsification with bilateral TIOL placement performed outside CCAD. The right eye had $360^{\circ}$ of posterior synechiae that required synechialysis. Bilaterally, the TIOLs were encased within fibrotic capsular bags and dissection resulted in partial intraoperative zonular loss. The right eye required use of an Ahmed capsular tension ring (CTR) segment (FCl Ophthalmics, USA) that was scleral-sutured to improve centration and stabilization of the monofocal IOL in the capsular bag. The left eye required amputation and retention of one of the TIOL footplates. The 2 eyes with the longest duration of 72 months between initial phacoemulsification and IOL exchange experienced no intraoperative complications. Five of the 6 eyes eventually underwent Nd:YAG laser capsulotomy staged at least 3 months after IOL exchange. 
IOL exchange outcome data are shown in Table 4. The average follow-up interval for each patient was 28.8 months (range 14 to 41 months). The logMAR UDVA and CDVA were 0.17 (range 0 to 0.854 ) and 0 (range -0.12 to 0.10 ) respectively. Mean MRSE was $-0.46 \mathrm{D}$ (range 0.25 to -1.38 ) and only 2 eyes had residual refractive astigmatism $>0.5 \mathrm{D}$. Subjective visual complaints resolved in all patients. UDVA and MRSE improved in each eye except for case 6 which had a refractive surprise of MRSE -1.38D. The patient was plano in the other eye and required no additional surgery after adaptation to monovision. All patients stated they would undergo IOL exchange again. Objective mean changes in UDVA, CDVA, MRSE and residual refractive astigmatism were not statistically significant. The results are shown in Table 5.

\section{Discussion}

MFIOLs increase spectacle independence in pseudophakic patients by correcting presbyopia. TIOLs are a subcategory of MFIOL that work by diffracting light into three separate focal points for distance, intermediate and near [1, 2, 4]. Appropriate patient selection, including exclusion of patients with many forms of irreversible ocular disease, is critical to success. TIOL technology has potential drawbacks, including photic phenomena and decreased contrast sensitivity in mesopic conditions $[12,13]$. Psychophysical halometry demonstrates that the double halo pattern produced by TIOL's tends to elicit fewer visual complaints than the single halo pattern produced by commercially-available BIOL's [14]. However, clinically significant haloes persist in approximately $40 \%$ of patients at a period of 3-6 months after TIOL placement $[1,15,16]$ and can be bothersome in $5 \%$ of patients [16]. Studies also show that it may require 3 months for neuroadaptation to occur after $\operatorname{MFIOL}$ placement $[6,17,18]$.

Although a wide variety of MFIOLs are implanted in the UAE, a comprehensive review of the CCAD electronic medical record system for MFIOL exchange of any IOL type revealed that the only MFIOL that required exchange during the study period was the AT LISA TIOL. The AT LISA combines a central $4.3 \mathrm{~mm}$ diameter trifocal area with a bifocal diffractive surface between 4.3 to $6 \mathrm{~mm}$. The lens is available in both toric (model 939) and non-toric (model 839) versions, and can come preloaded (MP) or non-preloaded (M). The AT LISA TIOL provides good contrast sensitivity and excellent uncorrected distance, intermediate and near visual outcomes in well-selected patient populations resulting in high rates of spectacle independence and patient satisfaction $[1,15,18]$.

With regard to overall MFIOL available to our patients regionally, BIOL's were the first MFIOL's widely implanted in the UAE, but these patients represent only a small number of patients with MFIOL's presenting to our practice. In 2012, the AT LISA was the first TIOL available in the UAE. The Panoptix IQ TIOL (Alcon Laboratories, Inc.) became available later in Fall 2014. As these newer IOL's emerged, the market shifted from BIOL to TIOL technology, and overall MFIOL implantation numbers are currently estimated to be in the thousands yearly. EDOF IOL's have more recently become available in UAE, but most were implanted after our designated study period. It's important to note that our clinic cares for a substantial number of (both) expatriates and local patients who have participated in medical tourism abroad, where a larger variety of MFIOL's may have been implanted.

In this case series, 5 of 6 eyes presented with > 0.5D of residual refractive cylinder, which has been correlated with patient dissatisfaction after MFIOL placement $[19,20]$. Despite correcting refractive error with spectacle correction, none of our patients experienced subjective improvement in vision. We believe this is due to the presence of additional ocular comorbidities in our series of patients.

MFIOL implantation is contraindicated in the setting of ocular comorbidities that could further impact visual quality $[5,21,22]$. There is no evidence to suggest that TIOL's are any more or less forgiving relative to ocular comorbidities than BIOL's, as studies have shown equivocal outcomes related to contrast sensitivity outcomes between TIOL's and BIOL's $[3,13,23]$. Contraindications to BIOL and TIOL placement include, but are not limited to: corneal disease, untreated dry eye syndrome, abnormal/irregular tomography/topography, mydriasis/miosis, zonular instability/loss, macular disease and optic nerve disease [5]. Chronic or recurrent uveitis is an absolute contraindication for MFIOL placement, given this disease's potential to negatively impact multiple parts of the ocular system. If there are potentially reversible comorbidities, such as untreated dry eye, map dot fingerprint dystrophy, pterygia or Salzmann nodules, we advise treating those conditions to resolution before consideration of MFIOL placement.

Corneal tomography is advised to check for abnormalities such as irregular astigmatism, increased higher order aberrations (HOA) and increased angle kappa. One of the patients in our series had $-0.61 \mu \mathrm{m}$ of horizontal corneal coma and angle kappa of $0.66 \mathrm{~mm}$, as shown in Figure 1. Following primary cataract surgery, this patient suffered from visually significant haloes that weren't ameliorated by miotic drops or blue light $(470 \mathrm{~nm})$ filtering eyeglasses. It has been reported that coma values $> \pm 0.33 \mu \mathrm{m}$ are problematic for MFIOL's, as these patients may experience intolerable photic phenomena [24]. Alternatively, others recommend avoiding MFIOL technology when corneal HOA's exceed average $+2.00 \mathrm{SD}$ of total HOA's, $\pm 0.30 \mu \mathrm{m}$ of coma, $\pm 0.40 \mu \mathrm{m}$ of trefoil, $\pm 0.30 \mu \mathrm{m}$ of quatrefoil, $\pm 0.20 \mu \mathrm{m}$ of 
fifth-order aberrations, or angle kappa is $>0.4$ to $0.5 \mathrm{~mm}$, as these abnormalities may decrease visual quality and increase the incidence of haloes and glare [25-27].

Preoperative dilated fundus examination and retina ocular coherence tomography (OCT) are advised to check for macular disease, as it is estimated that more than a quarter of patients undergoing phacoemulsification may have concurrent macular pathology [28]. Diabetes remains a relative contraindication to bifocal or TIOL technology, and there is no definitive guidance in this regard. We advise avoiding TIOL placement in any patient with diabetic retinopathy, diabetic macular edema and/or historical poor blood sugar control. If there is no evidence of diabetic retinopathy and a history of well-controlled blood sugars with adherence to diet and medication therapy, the surgeon and patient may consider TIOL placement. However, the patient should be informed that IOL exchange might be necessary if diabetic macular disease occurs in the future. One eye in this series had focal interruption in the ellipsoid zone in the fovea, as shown in Figure 2. The patient complained of blurred vision at all distances after TIOL placement. In this particular case, the findings were only evident on retinal OCT, which has been shown to be more sensitive than stereoscopic retinal examination. Nearly 7 to $11 \%$ of normalappearing retinas may harbor subtle macular pathologies that can only be reliably detected on OCT [29, 30]. Although a preoperative screening OCT adds additional cost to cataract workup, it has been shown to be cost-effective by facilitating appropriate IOL selection by the patient and surgeon [29]. For cataract surgeons inexperienced with retinal OCT interpretation, this is one future potentially simple and useful application for artificial intelligence in the classification of normal from abnormal scans.

There are several published decision trees for managing patients that are intolerant to MFIOL placement [5-7]. The first step is to assess the subjective experience of the patient and to address his/her individual concerns [5]. Many problems can be effectively managed with a variety of minimally invasive treatment modalities specific to the complaint [7]. Second, treat reversible ocular comorbidities. A recent study by Seiler et al [20] found that residual refractive astigmatism $>0.5 \mathrm{D}$ was the most common cause of patient dissatisfaction following placement of a TIOL. $26 \%$ of the eyes required subsequent selective wavefront-guided laser in situ keratomileusis to achieve satisfaction. We advise considering laser refractive correction if the patient improves with a trial of refractive correction but does not want to use spectacles or contact lenses. Dry eye syndrome is also a common confounder and we recommend initiating and escalating treatment per an established dry eye management protocol [9].

For patients experiencing bothersome photic phenomena, inhibition of mydriasis with topical brimonidine tartrate $0.2 \%$ on an as-needed basis can help to ameliorate the symptoms [7]. We have anecdotal experience suggesting that blue light filtering eyeglasses (470nm) reduces photic phenomena in some patients. This is consistent with published findings demonstrating that blue-filtering IOL's may play a role in glare reduction in pseudophakic patients [31].

Clinically significant PCO is common after TIOL placement [32]. In a multi-center retrospective analysis looking at rates of Nd:YAG laser capsulotomy, investigators found the capsulotomy rates to be $23 \%$ following AT LISA placement [32]. Nd:YAG laser capsulotomy should be reserved until other potential problems have been ruled out and addressed, especially if the extent and density of the capsular opacity is disproportionate to the symptoms.

If there are ocular comorbidities that cannot be ameliorated, IOL exchange can be undertaken even years after initial IOL implantation [8]. For biometry prior to IOL exchange, we recommend using the Barrett Rx Exchange formula in cases where pre-phacoemulsification biometric data is available. This formula is derived from both the Barrett Universal II and Barrett Toric Calculator formulae. It calculates spherical power and, if needed, the optimal cylinder power and alignment of the new IOL [33]. Lacking historical data, one should use a $3^{\text {rd }}$ generation IOL formula that does not estimate effective lens position (ELP) based on anterior chamber depth measurement (ACD). One eye in our study underwent calculation with the Holladay 2 formula on the IOL Master in the pseudophakia setting, but the ACD artificially overestimated ELP and resulted in myopic surprise.

IOL exchange can be challenging. The most common intraoperative complications include capsular rupture, vitreous loss and zonular rupture [10,34]. In this study, surgical complexity was highest in the 2 eyes from the same patient with bilateral intermediate uveitis and severe capsular fibrosis bilaterally. We recommend a bimanual surgical technique along with meticulous viscodissection and/or haptic amputation in cases of severe capsular contraction or fibrosis. In cases of zonular loss and capsular bag instability/decentration, be prepared to implement capsule support and refixation devices combined with scleral-fixation techniques in order to stabilize and recenter the IOL-capsular bag complex. Scleral-fixated capsular tension segments may be preferable to modified CTR's, as fibrosed capsular bags may not be amenable to placement of a CTR. The IOL scaffold technique has been shown to be safe and effective and can potentially reduce the risk for vitreous loss and posterior capsule rupture [11]. In cases of an open posterior capsule, this technique also prevents posterior dislocation of the IOL optic during transection [11]. Be prepared for anterior vitrectomy if vitreous presents and

Page 5/10 
have a backup 3-piece IOL in case sulcus IOL placement is necessary. Alternatively, in the event that an IOL cannot be safely inserted into the capsular bag or sulcus, a scleral-fixated, iris-fixated, or anterior chamber IOL can be considered.

There are several limitations to this study. First, the AT LISA TIOL was the only MFIOL exchanged in our study. This study was conducted as a single-institution, retrospective chart review, whereas we know MFIOL's are implanted and presumably exchanged elsewhere in the region. Thus, we are unable to calculate the comparative regional rate or overall incidence of MFIOL exchange within the scope of this study. Second, the sample size in this study is small. Although the improvement in standard mean differences from preoperative to postoperative UDVA, CDVA, MRSE and residual refractive error are quite large, we would need more eyes to demonstrate statistical significance. Third, neither contrast sensitivity assessment nor quality of vision surveys are routinely measured as a part of the clinical workup of patients in our clinic, so this quantitative data is not included in the analysis.

Although we know TIOL's provide high levels of spectacle independence and patient satisfaction, our experience suggests that patient selection is critical to success, similar to other MFIOL's. When patients are intolerant to MFIOL technology, particularly in the setting of irreversible ocular comorbidities, our results demonstrate that IOL exchange is an effective and safe surgical option. IOL exchange to a monofocal IOL resulted in subjective improvement in vision by the last follow up appointment in each of our patients.

\section{Declarations}

Author Contributions: BA was responsible for designing the study, collecting and analysing data, writing and submitting the article. JAG, TL and SN were responsible for designing the study, analysing data and editing the manuscript.

Funding Info: The authors have no relevant financial interests to disclose.

Competing Interests: The authors have no competing interests to disclose.

Data Availability: All data is included within the manuscript.

Ethics approval: This study was approved by the Cleveland Clinic Abu Dhabi (CCAD) Institutional Review Board and conducted in accordance with the tenets of the Declaration of Helsinki.

Consent to participate: Not Applicable

Animal Research (Ethics): Not Applicable

Consent to Publish: All authors have agreed to the submission and publication of the paper in this journal.

\section{References}

1. Law EM, Aggarwal RK, Kasaby H Clinical outcomes with a new trifocal intraocular lens. Eur J Ophthalmol 24:501-8. https://doi.org/10.5301/ejo.5000407

2. Mencucci R, Favuzza E, Caporossi O, et al (2018) Comparative analysis of visual outcomes, reading skills, contrast sensitivity, and patient satisfaction with two models of trifocal diffractive intraocular lenses and an extended range of vision intraocular lens. Graefe's Arch Clin Exp Ophthalmol 256:1913-1922. https://doi.org/10.1007/s00417-018-4052-3

3. Shen Z, Lin Y, Zhu Y, et al (2017) Clinical comparison of patient outcomes following implantation of trifocal or bifocal intraocular lenses: A systematic review and meta-analysis. Sci Rep 7:1-9. https://doi.org/10.1038/srep45337

4. Mendicute J, Kapp A, Lévy P, et al (2016) Evaluation of visual outcomes and patient satisfaction after implantation of a diffractive trifocal intraocular lens. J Cataract Refract Surg 42:203-10. https://doi.org/10.1016/j.jcrs.2015.11.037

5. Braga-Mele R, Chang D, Dewey S, et al (2014) Multifocal intraocular lenses: Relative indications and contraindications for implantation. J Cataract Refract Surg 40:313-322. https://doi.org/10.1016/j.jcrs.2013.12.011

6. Alio JL, Plaza-Puche AB, Férnandez-Buenaga R, et al (2017) Multifocal intraocular lenses: An overview. Surv Ophthalmol 62:611634. https://doi.org/10.1016/j.survophthal.2017.03.005

7. Woodward MA, Randleman JB, Stulting RD (2009) Dissatisfaction after multifocal intraocular lens implantation. J Cataract Refract Surg 35:992-7. https://doi.org/10.1016/j.jcrs.2009.01.031

Page 6/10 
8. Kamiya K, Hayashi K, Shimizu K, et al (2014) Multifocal intraocular lens explantation: A case series of 50 eyes. Am J Ophthalmol 158:215-220.e1. https://doi.org/10.1016/j.ajo.2014.04.010

9. Subcommittee T (2007) Management and therapy of dry eye disease: report of the Management and Therapy Subcommittee of the International Dry Eye WorkShop (2007). Ocul Surf 5:163-78. https://doi.org/10.1016/S1542-0124(12)70085-X

10. Kim EJ, Sajjad A, Montes de Oca I, et al (2017) Refractive outcomes after multifocal intraocular lens exchange. J Cataract Refract Surg 43:761-766. https://doi.org/10.1016/j.jcrs.2017.03.034

11. Narang P, Steinert R, Little B, Agarwal A (2014) Intraocular lens scaffold to facilitate intraocular lens exchange. J Cataract Refract Surg 40:1403-1407. https://doi.org/10.1016/j.jcrs.2014.07.015

12. Martinez-de-la-Casa JM, Carballo-Alvarez J, Garcia-Bella J, et al Photopic and Mesopic Performance of 2 Different Trifocal Diffractive Intraocular Lenses. Eur J Ophthalmol 27:26-30. https://doi.org/10.5301/ejo.5000814

13. Plaza-Puche AB, Alio JL, Sala E, Mojzis $P$ (2016) Impact of low mesopic contrast sensitivity outcomes in different types of modern multifocal intraocular lenses. Eur J Ophthalmol 26:612-617. https://doi.org/10.5301/ejo.5000777

14. Alba-Bueno F, Garzón N, Vega F, et al (2018) Patient-Perceived and Laboratory-Measured Halos Associated with Diffractive Bifocal and Trifocal Intraocular Lenses. Curr Eye Res 43:35-42. https://doi.org/10.1080/02713683.2017.1379541

15. Mojzis P, Majerova K, Plaza-Puche AB, et al (2015) Visual outcomes of a new toric trifocal diffractive intraocular lens. J Cataract Refract Surg 41:2695-2706. https://doi.org/10.1016/j.jcrs.2015.07.033

16. Kretz FTA, Breyer D, Diakonis VF, et al (2015) Clinical Outcomes after Binocular Implantation of a New Trifocal Diffractive Intraocular Lens. J Ophthalmol 2015:. https://doi.org/10.1155/2015/962891

17. Monaco G, Gari M, Di Censo F, et al (2017) Visual performance after bilateral implantation of 2 new presbyopia-correcting intraocular lenses: Trifocal versus extended range of vision. J Cataract Refract Surg 43:737-747. https://doi.org/10.1016/j.jcrs.2017.03.037

18. Kohnen T, Titke C, Böhm M (2016) Trifocal Intraocular Lens Implantation to Treat Visual Demands in Various Distances Following Lens Removal. Am J Ophthalmol 161:71-77.e1. https://doi.org/10.1016/j.ajo.2015.09.030

19. McNeely RN, Pazo E, Millar Z, et al (2016) Threshold limit of postoperative astigmatism for patient satisfaction after refractive lens exchange and multifocal intraocular lens implantation. J Cataract Refract Surg 42:1126-1134.

https://doi.org/10.1016/j.jcrs.2016.05.007

20. Seiler TG, Wegner A, Senfft T, Seiler T (2019) Dissatisfaction after trifocal IOL implantation and its improvement by selective wavefront-guided LASIK. J Refract Surg 35:346-352. https://doi.org/10.3928/1081597X-20190510-02

21. Sachdev GS, Sachdev M (2017) Optimizing outcomes with multifocal intraocular lenses. Indian J Ophthalmol 65:1294-1300. https://doi.org/10.4103/ijo.IJO_1072_17

22. De Vries NE, Nuijts RMMA (2013) Multifocal intraocular lenses in cataract surgery: Literature review of benefits and side effects. J Cataract Refract Surg 39:268-278. https://doi.org/10.1016/j.jcrs.2012.12.002

23. Jonker SMR, Bauer NJC, Makhotkina NY, et al (2015) Comparison of a trifocal intraocular lens with a +3.0 D bifocal IOL: Results of a prospective randomized clinical trial Presented at the XXXI Congress of the European Society of Cataract and Refractive Surgeons, Amsterdam, the Netherlands, October 2013. J Cataract Refract Surg 41:1631-1640.

https://doi.org/10.1016/j.jcrs.2015.08.011

24. Hill W (2013) Higher order aberrations and diffractive multifocal IOLs. In: Suppl. to Cataract Refract. Surg. Today. www.crstoday.com/wp-content/themes/crst/assets/downloads/1013_supp.pdf

25. Arce C (2013) Avoiding Visual Complaints With Premium IOLs. In: Suppl. to Cataract Refract. Surg. Today Eur. www.crstodayeurope.com/wp-content/themes/crste/assets/downloads/1013_supp.pdf

26. Qi Y, Lin J, Leng L, et al (2018) Role of angle $\mathrm{k}$ in visual quality in patients with a trifocal diffractive intraocular lens. J Cataract Refract Surg 44:949-954. https://doi.org/10.1016/j.jcrs.2018.05.026

27. Fu Y, Kou J, Chen D, et al (2019) Influence of angle kappa and angle alpha on visual quality after implantation of multifocal intraocular lenses. J Cataract Refract Surg 45:1258-1264. https://doi.org/10.1016/j.jcrs.2019.04.003

28. Abdelmassih Y, El-Khoury S, Georges S, et al (2018) Preoperative spectral-domain optical coherence tomography in patients having cataract surgery. J Cataract Refract Surg 44:610-614. https://doi.org/10.1016/j.jcrs.2018.02.020

29. Leung EH, Gibbons A, Koch DD (2020) Cost-Effectiveness of Preoperative OCT in Cataract Evaluation for Multifocal Intraocular Lens. Ophthalmology 127:859-865. https://doi.org/10.1016/j.ophtha.2020.01.049

Page $7 / 10$ 
30. Pinto WP, Rabello LP, Ventura MC, et al (2019) Prevalence of macular abnormalities identified only by optical coherence tomography in Brazilian patients with cataract. J Cataract Refract Surg 45:915-918. https://doi.org/10.1016/j.jcrs.2019.01.022

31. Davison JA, Patel AS, Cunha JP, et al (2011) Recent studies provide an updated clinical perspective on blue light-filtering IOLs. Graefe's Arch Clin Exp Ophthalmol 249:957-968. https://doi.org/10.1007/s00417-011-1697-6

32. Bilbao-Calabuig R, Llovet-Osuna F, González-López F, Beltrán J (2016) Nd:YAG Capsulotomy rates with two trifocal intraocular lenses. J Refract Surg 32:748-752. https://doi.org/10.3928/1081597X-20160803-02

33. Tipperman R (2018) The Barrett Rx Formula: A new tool for managing power surprises with toric IOLs. In: Glaucoma Today. www.glaucomatoday.com/articles/2018-mar-apr/the-barrett-rx-formula

34. Leysen I, Bartholomeeusen E, Coeckelbergh T, Tassignon MJBR (2009) Surgical outcomes of intraocular lens exchange. Five-year study. J Cataract Refract Surg 35:1013-1018. https://doi.org/10.1016/j.jcrs.2009.01.024

\section{Tables}

\begin{tabular}{|c|c|c|c|c|c|c|c|c|}
\hline Eye & Age & Sex & Laterality & Date of Phaco & Facility & Phaco Complications & IOL & IOL Location \\
\hline$\# 1$ & 36 & M & Right & 1Jun'15 & External & $\mathrm{N} / \mathrm{A}$ & AT LISA TIOL & Capsule \\
\hline \#2 & 36 & M & Left & 15Jun'15 & External & $\mathrm{N} / \mathrm{A}$ & AT LISA TIOL & Capsule \\
\hline \#3 & 67 & $\mathrm{~F}$ & Right & 15May'16 & CCAD & $\mathrm{N} / \mathrm{A}$ & AT LISA TIOL & Capsule \\
\hline \#4 & 53 & $\mathrm{~F}$ & Left & 2012 & External & $\mathrm{N} / \mathrm{A}$ & AT LISA TIOL & Capsule \\
\hline \#5 & 64 & $\mathrm{~F}$ & Right & 2012 & External & Anterior Capsule Tear & AT LISA TIOL & Capsule \\
\hline \#6 & 62 & $M$ & Right & 5Feb'17 & CCAD & $\mathrm{N} / \mathrm{A}$ & AT LISA TIOL & Capsule \\
\hline
\end{tabular}

\begin{tabular}{|c|c|c|c|c|c|c|c|}
\hline Eye & $\begin{array}{l}\text { UDVA } \\
\text { (Snellen) }\end{array}$ & $\begin{array}{l}\text { Refractive } \\
\text { Error }\end{array}$ & $\begin{array}{l}\text { MRSE } \\
\text { (D) }\end{array}$ & $\begin{array}{l}\text { CDVA } \\
\text { (Snellen) }\end{array}$ & UNVA & Visual Complaint(s) & Ocular Comorbidities \\
\hline$\# 1$ & $20 / 50$ & $\begin{array}{l}-1.75 / 0.75 \\
\times 155\end{array}$ & -1.38 & $20 / 20$ & $\mathrm{~N} / \mathrm{A}$ & $\begin{array}{l}\text { Blurred Vision } \\
\text { Monocular Diplopia }\end{array}$ & $\begin{array}{l}\text { Intermediate Uveitis, Keraoconjunctivitis } \\
\text { Sicca, } 1+\text { PCO, } 360^{\circ} \text { Posterior Synechiae }\end{array}$ \\
\hline \#2 & $20 / 150$ & $\begin{array}{l}-2.00 / 0.75 \\
\times 25\end{array}$ & -1.63 & $20 / 25$ & $\mathrm{~N} / \mathrm{A}$ & $\begin{array}{l}\text { Blurred Vision } \\
\text { Monocular Diplopia }\end{array}$ & $\begin{array}{l}\text { Intermediate Uveitis, Keraoconjunctivitis } \\
\text { Sicca, 1+ PCO }\end{array}$ \\
\hline \#3 & $20 / 40$ & $\begin{array}{l}-0.75 / 0.75 \\
\times 3\end{array}$ & -0.38 & $20 / 25$ & J1 & Blurred Vision & $\begin{array}{l}\text { Interruption of ellipsoid zone in the fovea, } \\
\text { Dry Eye }\end{array}$ \\
\hline \#4 & $20 / 100$ & $\begin{array}{l}-1.25 / 1.5 \\
\times 178\end{array}$ & -0.50 & $20 / 25$ & J3 & $\begin{array}{l}\text { Hazy Vision } \\
\text { (Underwater vision) }\end{array}$ & $\begin{array}{l}\text { Sjogrens Syndrome, } 1+\text { PCO, } \\
\text { Hydroxychloroquine Use }\end{array}$ \\
\hline \#5 & $20 / 80$ & $\begin{array}{l}-1.00 / 1.00 \\
\times 102\end{array}$ & -0.50 & $20 / 60$ & J7 & $\begin{array}{l}\text { Blurred vision, } \\
\text { Negative } \\
\text { Dysphotopsia }\end{array}$ & Diabetic Macular Edema, Dry Eye, 1+ PCO \\
\hline \#6 & $20 / 20$ & $\begin{array}{l}-0.50 / 0.5 \\
\times 160\end{array}$ & -0.25 & $20 / 15$ & J1 & $\begin{array}{l}\text { Positive } \\
\text { Dysphotopsia } \\
\text { (Haloes) }\end{array}$ & $\begin{array}{l}\text { Increased HOA's, Increased Angle Kappa, Dry } \\
\text { eye, Trace PCO }\end{array}$ \\
\hline $\begin{array}{l}\text { UD } \\
\text { Dis } \\
\mathrm{Ab}\end{array}$ & $\begin{array}{l}\text { Uncorre } \\
\text { e Visual } \\
\text { ons }\end{array}$ & bistance & A & MRSE & if $f$ & $\begin{array}{l}\text { fractive Spherical } \\
\mathrm{CO}=\text { Posterior } \mathrm{Ca}\end{array}$ & $\begin{array}{l}\text { ivalent, } \mathrm{D}=\text { Diopters, } \mathrm{CDVA}=\text { Corrected } \\
\text { ar Opacification, HOA = Higher Order }\end{array}$ \\
\hline
\end{tabular}




\begin{tabular}{|c|c|c|c|c|c|c|c|}
\hline Eye & $\begin{array}{l}\text { Time Between } \\
\text { Surgeries (Months) }\end{array}$ & $\begin{array}{l}\text { IOL } \\
\text { Exchange } \\
\text { Formula }\end{array}$ & $\begin{array}{l}\text { IOL Exchange } \\
\text { Technique }\end{array}$ & $\begin{array}{l}\text { Intraoperative } \\
\text { Complications }\end{array}$ & $\begin{array}{l}\text { Postoperative } \\
\text { Complications }\end{array}$ & $\begin{array}{l}\text { IOL } \\
\text { Implanted }\end{array}$ & $\begin{array}{l}\text { IOL } \\
\text { Location } \\
\text { Fixation }\end{array}$ \\
\hline \#1 & 26 & Barrett Rx & $\begin{array}{l}\text { Standard }{ }^{1}+ \\
\text { Synechialysis }\end{array}$ & $\begin{array}{l}\text { Zonular } \\
\text { Dehisence }\end{array}$ & IOL Decentration & SN60WF & In the Bag \\
\hline \#2 & 26 & Barret Rx & IOL Scaffold & $\begin{array}{l}\text { Zonular } \\
\text { Dehiscence }\end{array}$ & IOL Decentration & MA60AC & In the Bag \\
\hline \#3 & 6 & Barrett Rx & IOL Scaffold & Iris Sphincer Tear & N/A & SN60WF & In the Bag \\
\hline \#4 & 72 & Holladay 1 & IOL Scaffold & N/A & $\mathrm{N} / \mathrm{A}$ & SN60WF & In the Bag \\
\hline \#5 & 72 & Barrett Toric & IOL Scaffold & $\mathrm{N} / \mathrm{A}$ & N/A & SN6AT4 & In the Bag \\
\hline \#6 & 19 & Holladay 2 & Standard ${ }^{1}$ & $\begin{array}{l}\text { Zonular } \\
\text { Dehiscence }\end{array}$ & $\begin{array}{l}\text { Refractive } \\
\text { Surprise }\end{array}$ & SN60WF & In the Bag \\
\hline
\end{tabular}

Table 4: IOL Exchange Outcome Data

Preoperative

\begin{tabular}{|c|c|c|c|c|c|c|c|c|c|c|}
\hline Eye & $\begin{array}{l}\text { UDVA } \\
\text { (logmar) }\end{array}$ & $\begin{array}{l}\text { CDVA } \\
\text { (logmar) }\end{array}$ & $\begin{array}{l}\text { Refractive } \\
\text { Cylinder }\end{array}$ & $\begin{array}{l}\text { Spherical } \\
\text { Equivalent }\end{array}$ & $\begin{array}{l}\text { IOL } \\
\text { Exchange } \\
\text { Formula }\end{array}$ & $\begin{array}{l}\text { Follow } \\
\text { Up } \\
\text { (Months) }\end{array}$ & $\begin{array}{l}\text { UDVA } \\
\text { (logmar) }\end{array}$ & $\begin{array}{l}\text { CDVA } \\
\text { (logmar) }\end{array}$ & $\begin{array}{l}\text { Refractive } \\
\text { Cylinder }\end{array}$ & $\begin{array}{l}\text { Spherical } \\
\text { Equivalent }\end{array}$ \\
\hline$\# 1$ & 0.40 & 0.00 & 0.75 & -1.38 & Barrett Rx & 32 & 0.10 & 0.10 & 0.5 & -0.50 \\
\hline \#2 & 0.88 & 0.10 & 0.75 & -1.63 & Barrett Rx & 32 & 0.18 & 0.00 & 0.25 & -0.63 \\
\hline \#3 & 0.30 & 0.10 & 0.75 & -0.38 & Barrett Rx & 41 & 0.10 & 0.00 & 0.5 & 0.25 \\
\hline \#4 & 0.70 & 0.10 & 1.50 & -0.50 & $\begin{array}{l}\text { Holladay } \\
1\end{array}$ & 21 & 0.10 & -0.12 & 1.5 & 0.00 \\
\hline \#5 & 0.60 & 0.48 & 1.00 & -0.50 & $\begin{array}{l}\text { Barrett } \\
\text { Toric }\end{array}$ & 33 & 0.00 & 0.00 & 0.5 & -0.50 \\
\hline \#6 & 0.00 & -0.12 & 0.50 & -0.25 & $\begin{array}{l}\text { Holladay } \\
2\end{array}$ & 14 & 0.54 & 0.00 & 0.75 & -1.38 \\
\hline
\end{tabular}

\begin{tabular}{|c|c|c|c|c|c|c|c|}
\hline \multirow[t]{2}{*}{ Endpoints } & & \multicolumn{2}{|c|}{ PreOperative } & \multicolumn{2}{|c|}{ PostOperative } & \multicolumn{2}{|l|}{ Mean Difference } \\
\hline & & Mean & Std Dev & Mean & Std Dev & p-value (2-tailed) & p-value (1-tailed) \\
\hline \multirow[t]{2}{*}{ Distance Visual Acuity } & Uncorrected (logmar) & 0.48 & 0.31 & 0.17 & 0.19 & 0.16 & 0.08 \\
\hline & Corrected (logmar) & 0.11 & 0.2 & 0 & 0.07 & 0.27 & 0.14 \\
\hline \multirow[t]{2}{*}{ Manifest Refraction } & Spherical Equivalent & -0.77 & 0.58 & -0.46 & 0.56 & 0.38 & 0.19 \\
\hline & Refractive Cylinder & 0.88 & 0.34 & 0.67 & 0.44 & 0.14 & 0.07 \\
\hline
\end{tabular}

\section{Figures}



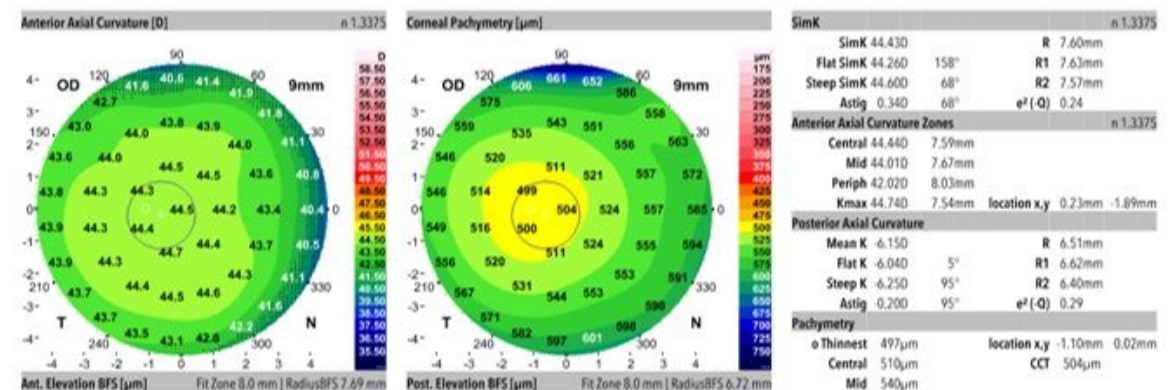

Total Corneal Wavefrom Zemike Coeffcianns [um]

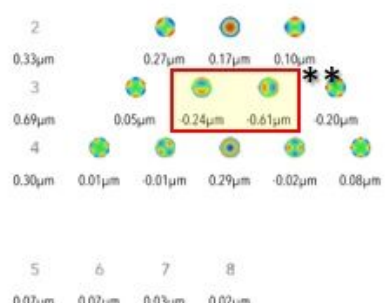

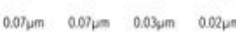

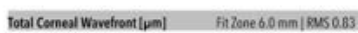

Tocal Comed Waveftont Ple Chantip]

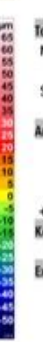

Mid 500,um
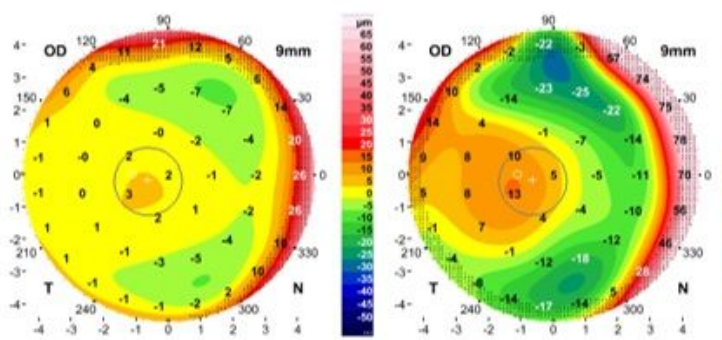

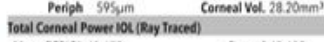

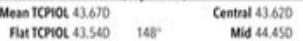

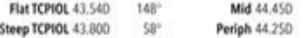

Steep TChOL 43.000 Astig $0.260 \quad 58^{\circ}$ WTW, NF $12.20 \mathrm{~mm}$ $\begin{array}{lll}A C V & 101 \mathrm{~mm}^{3} \\ \text { AOO } 244 \mathrm{~mm}\end{array}$

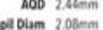
CiMlas 0.320 ClMiss 0.320

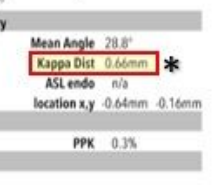

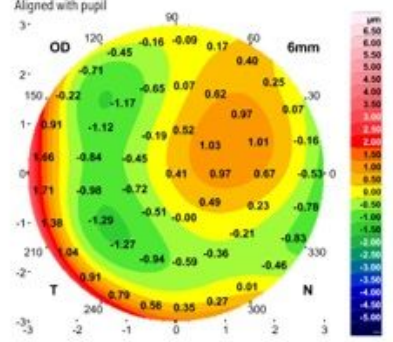

Coma 0.130
Total Corneal Woveftront Zemile Coefficiants [D]

Defocus 1 astigmatism 2 2. Onder $\odot$ Spericicl 021.7 Irefolil 0.1600115 .3 .0230

Other HOA 58

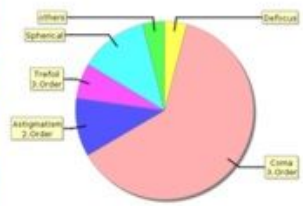

\section{Figure 1}

Corneal tomography of eye \#6 demonstrating increased angle kappa $\left.{ }^{*}\right)$ and corneal coma $(* *)$
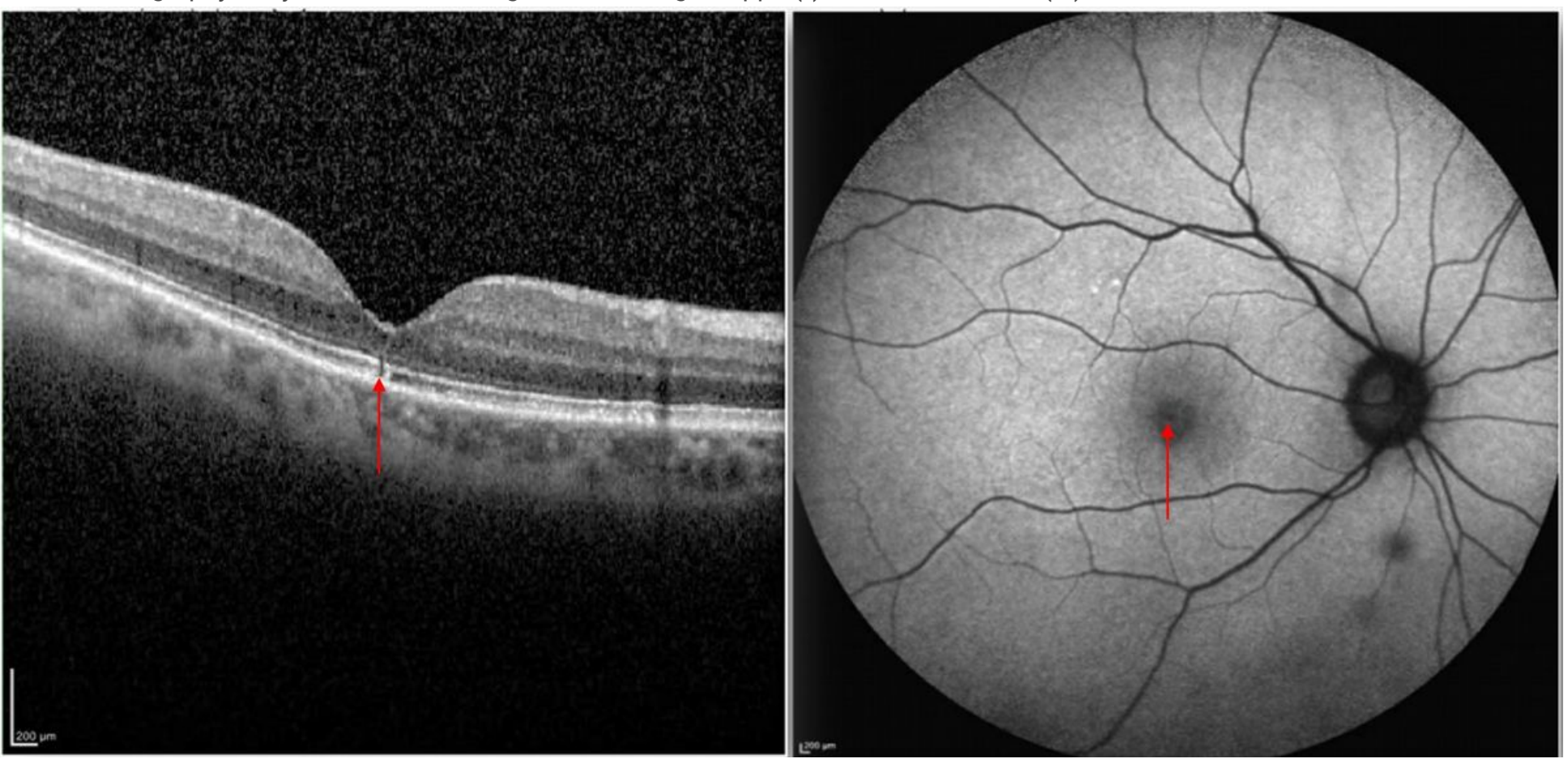

Figure 2

Macula ocular coherence tomography and fundus autofluorescence showing subtle macular pathology in eye \#3 representing focal interruption in the ellipsoid zone in the fovea (red arrow) 